BRITISH MEDICAL JOURNAL VOLUME $294 \quad 16$ MAY 1987

eight subjects were calculated as the mean of differences $\pm 2 \cdot 36 \times$ standard error.

\section{Results}

All subjects had normal fasting plasma glucose concentrations (table I). Peak plasma glucose concentrations after the glucose solutions whether supplemented or not with salt were higher than those after the macaroni meals ( $p<0.05$ in both cases). No significant effect on plasma glucose responses was observed after adding salt to the two test meals (table I). Similarly, no differences in the areas under the plasma glucose curves were discernible (table II).

\section{Discussion}

In contrast with Thorburn et $a l,{ }^{3}$ we found no significant difference in glycaemic responses to test meals with and without added salt. The median peak plasma glucose values were almost identical for each test meal with and without the addition of salt. Though there was a trend towards an increase in the glucose absorption rate after the glucose solution with added salt, this did not reach significance owing to the considerable variability in glucose responses. On the other hand, the opposite trend was seen after the macaroni meal, suggesting that adding salt to a carbohydrate meal is unlikely to have a substantial influence on the glycaemic response. As the rate of ingestion of the carbohydrate load was standardised and no significant differences were found in the glycaemic responses to salted and unsalted test meals at the various

TABLE I-Fasting and peak plasma glucose concentrations after test meals in the eight subjects

\begin{tabular}{|c|c|c|c|}
\hline & $\begin{array}{c}\text { Median (range) } \\
\text { fasting plasma } \\
\text { glucose } \\
(\mathrm{mmol} / \mathrm{l})\end{array}$ & $\begin{array}{c}\text { Median (range) } \\
\text { peak plasma } \\
\text { glucose } \\
(\mathrm{mmol} / \mathrm{l})\end{array}$ & $\begin{array}{c}\text { p Value; } \\
95 \% \text { confidence } \\
\text { interval }\end{array}$ \\
\hline $\begin{array}{l}\text { Glucose solution } \\
\text { Glucose solution with salt }\end{array}$ & $\begin{array}{l}4 \cdot 6(4 \cdot 1-4 \cdot 9) \\
4 \cdot 6(4 \cdot 1-4 \cdot 9)\end{array}$ & $\left.\begin{array}{l}7 \cdot 8(5 \cdot 7-8 \cdot 5) \\
7 \cdot 6(6 \cdot 3-9 \cdot 0)\end{array}\right\}$ & 0.401 (NS); -0.53 to 1.03 \\
\hline $\begin{array}{l}\text { Macaroni } \\
\text { Macaroni with salt }\end{array}$ & $\begin{array}{l}4 \cdot 6(4 \cdot 2-5 \cdot 0) \\
4 \cdot 6(4 \cdot 5-4 \cdot 9)\end{array}$ & $\left.\begin{array}{l}6 \cdot 1(5 \cdot 6-7 \cdot 0) \\
6 \cdot 5(4 \cdot 6-7 \cdot 5)\end{array}\right\}$ & 0.726 (NS); -0.84 to 0.69 \\
\hline
\end{tabular}

TABLE II-Areas under plasma glucose curves before and after adding salt to the two test meals

\begin{tabular}{|c|c|c|}
\hline & $\begin{array}{c}\text { Median (range) } \\
\text { area under plasma glucose curve } \\
\text { (mmol min/l) }\end{array}$ & $\begin{array}{l}\text { p Value; } 95 \% \text { confidence } \\
\text { interval }\end{array}$ \\
\hline $\begin{array}{l}\text { Glucose solution } \\
\text { Glucose solution with salt }\end{array}$ & $\left.\begin{array}{r}57 \cdot 8(-63.00 \text { to } 220 \cdot 50) \\
103 \cdot 5(-163 \cdot 00 \text { to } 223 \cdot 50)\end{array}\right\}$ & $0.484(\mathrm{NS}) ;-49.05$ to 101.71 \\
\hline $\begin{array}{l}\text { Macaroni } \\
\text { Macaroni with salt }\end{array}$ & $\left.\begin{array}{l}93.4(-12.00 \text { to } 151.50) \\
60.5(-88.50 \text { to } 154.50)\end{array}\right\}$ & $0.263(\mathrm{NS}) ;-69.46$ to 25.46 \\
\hline
\end{tabular}

time intervals we did not think it necessary to assess plasma insulin concentrations. ${ }^{78}$ In these healthy volunteers no differences were expected, as neither insulin sensitivity nor $\beta$ cell function was influenced during these acute carbohydrate loading experiments. As expected, we confirmed the lower peak plasma glucose concentrations after the macaroni meal as compared with glucose.

This short term study does not support a beneficial effect of salt restriction on glycaemic control in diabetes. Nevertheless, the reported relation between insulin concentrations and blood pressure warrants further study.

\section{References}

1 Jenkins DJA, Wolever TMS, Taylor RH, et al. Glycemic index of foods: a physiological basis for carbohydrate exchange. Am 7 Clin Nutr 1981;34:362-6.

2 Ionescu-Tirgoviste C, Popa E, Sintu E, Mihalache N, Cheta D, Mincu I. Blood glucose and plasma insulin responses to various carbohydrates in type 2 (non-insulin-dependent) diabetes. Diabetologia 1983;24:80-4.

3 Thorburn AW, Brand JC, Truswell AS. Salt and the glycaemic response. Br Med $\mathrm{J}$ 1986;292:1697-9.

4 Berglund G, Larson B, Anderson O, et al. Body composition and glucose metabolism in hypertensive middle-aged males. Acta Med Scand 1976;200:163-9.

5 Lucas CP, Estigarriba JA, Darga LL, Reaven GM. Insulin and blood pressure in obesity. Hypertension 1985;7:702-6.

6 Fournier AM, Gadia MT, Kubrusly DB, Skyler JS, Sosenko JM. Blood pressure, insulin and glycaemia in nondiabetic subjects. $A m \mathcal{J}$ Med 1986;80:861-4.

7 Crapo $P$, Insel J, Sperling M, Kolterman DG. Comparison of serum glucose, insulin and glucagon responses to different types of complex carbohydrate in non insulin-dependent diabetic patients. responses to different types of co

8 Heine RJ, Hanning I, Morgan L, Alberti KGMM. The oral glucose tolerance test (OGTT): effect of rate of ingestion of carbohydrate and different carbohydrate preparations. Diabetes Care 1983;6:441-5.

(Accepted 3 February 1987)

\title{
Delayed cerebellar ataxia: a new complication of falciparum malaria?
}

\author{
NIMAL SENANAYAKE
}

\begin{abstract}
Twelve cases of an unusual phenomenon of ataxia were investigated in otherwise well, conscious patients recovering from a febrile attack of presumed falciparum malaria. The ataxia occurred as the fever was subsiding, usually after an afebrile period of two to four days. The delay between onset of fever and the ataxia was three to four weeks. Peripheral blood of all the patients contained gametocytes of Plasmodium falciparum, and
\end{abstract}

\footnotetext{
Department of Medicine, Faculty of Medicine, University of Peradeniya, Peradeniya, Sri Lanka

NIMAL SENANAYAKE, MD, MRCP, associate professor of medicine
}

in some cases ring stages. The ataxia was most noticeable in the legs and the clinical picture suggested selective impairment of the cerebellar system. Signs of improvement appeared in a few weeks but complete recovery took one to four months.

The most likely pathogenic mechanism of the ataxia in these cases was an immune reaction triggered by the malaria parasite and affecting the cerebellum or its connections, or both.

\section{Introduction}

Neurological manifestations of falciparum malaria range from coma ${ }^{1}$ to muscular paralysis. ${ }^{2}$ This paper draws attention to a unique ataxic syndrome seen recently in Sri Lanka, which may prove to be a new complication of the disease. The outstanding feature was 
selective impairment of the cerebellar system in otherwise well, conscious patients. Patients were afebrile when the ataxia set in, but their peripheral blood was positive for Plasmodium falciparum. Twelve cases of this unusual phenomenon investigated at the teaching hospital, Peradeniya, are reported here. The first two cases presented in March 1984 and the others two years later. Only cases with clear cut symptomatology seen up to the end of July 1986 are included.

\section{Case histories}

The 12 patients ( 11 men) were aged 18-42 years (median 30 ) and came from different parts of central, northern, and eastern Sri Lanka. Six were permanent residents in known malarious areas and two were temporary residents or regular visitors. The other four had contracted malaria during a single visit to a malarious area. The residents and regular visitors had suffered more than one attack of fever diagnosed as malaria, but the ataxia developed only in relation to the last attack. Initial treatment for the fever had been given at local hospitals and dispensaries. Cases in which thin blood films had been examined before treatment had shown $P$ falciparum. Drugs given were chloroquine and primaquine in two cases, chloroquine in three, and chloroquine or amodiaquine in five.

The ataxia developed as the fever subsided. The delay between onset of fever and onset of the ataxia was 21-26 days. Many patients had an afebrile period of two to four days before onset. In one patient (a permanent resident in a malarious area) the afebrile period was two weeks. Unsteadiness on walking was the first and most noticeable symptom in all cases. Other symptoms were unsteadiness of hands (three cases), vertigo (three), difficulty in talking (two), and headache (one). No patient had been comatose. The disability was maximum on the second or third day, but in some cases the symptoms progressed for up to two weeks. Three patients were bedridden because of severe ataxia.

The patients were first seen by us three days to eight weeks (median two weeks) after the onset of ataxia. Ataxia of gait shown by heel to toe walking was a constant feature. Other findings were an abnormal heel-knee-shin test in 10, dysdiadochokinesia in eight, abnormal finger-nose test showing dysmetria and intention tremor in six, nystagmus in six, and dysarthria in three. Asymmetry of the signs in the limbs was noted in five patients. The nystagmus was horizontal, phasic, and bidirectional. Other systems were normal except for a palpable spleen $(1 \mathrm{~cm})$ in one patient.

Investigations - The following studies and laboratory values showed nothing abnormal: urine analysis, erythrocyte sedimentation rate, white cell count, haemoglobin concentration, blood glucose concentration, blood urea concentration, liver function, Wassermann reaction, Widal's test, electrocardiography, electroencephalography, sensory (median and ulnar) and motor (median and common peroneal) nerve conduction and electromyography of limb muscles, and cerebrospinal fluid protein and glucose concentrations, cell counts, and bacterial culture. Peripheral blood films of all the patients contained gametocytes of $P$ falciparum, and in five patients ring stages were seen.

Treatment-An extended course of oral chloroquine $(600 \mathrm{mg}$ initially and $300 \mathrm{mg}$ daily for five days) and primaquine $60 \mathrm{mg}$ was given with a view to eradicating the parasitaemia. Blood films of four patients, however, continued to show sexual and asexual forms of the parasite, suggesting reinfection or recrudescence in two and chloroquine resistance in two. All four were subsequently treated with Fansidar (pyrimethamine and sulfadoxine). Three patients who were cleared of the parasitaemia but still having severe ataxia were given prednisolone empirically $(60 \mathrm{mg} /$ day for seven days and tailed off). One patient who had had severe ataxia for eight weeks showed a definite improvement within two days of starting prednisolone and was completely free of ataxia in 12 days. The other two patients also showed noticeable improvement. Other forms of treatment were prochlorperazine for vertigo and physiotherapy for patients with severe ataxia.

Prognosis-In general, signs of improvement appeared a few weeks after onset of the ataxia. Seven patients showed complete recovery in three to 16 weeks (median 10). The other patients were lost to follow up. Of the four patients who had persistent parasitaemia, two had a relapse of fever; none of them, however, had a relapse or an exacerbation of the ataxia.

\section{Discussion}

The neurological signs in these cases suggested bilateral impairment of the cerebellum or its connections, or both. As this stereotyped clinical picture developed after presumed falciparum malaria and in association with a positive blood film it is reasonable to assume that a causal relation existed between the malarial attack and the ataxia. Theoretically, there are several possible pathogenic mechanisms: (a) a drug effect-for example, direct toxicity or idiosyncrasy or a toxic contaminant; $(b)$ effect of the parasite itselffor example, direct invasion, a toxic effect, or an immune reaction; and $(c)$ activation of a neurotropic virus.

A drug effect is unlikely because no common drug was given to all 12 patients. At least one patient was certain that he had not taken any antimalarial drug during the previous three months; and, in any case, antimalarials are not known to produce cerebellar ataxia. If we postulate ethnic and other host factors peculiar to Sri Lanka we should expect this adverse effect to occur after treatment of vivax malaria, which is much commoner than falciparum malaria in the area. On the same grounds a toxic contaminant can be discounted; the fact that several different brands of the same drug had been used is a further argument against a contaminant.

Direct invasion by the organism might damage the cerebellar system by causing vascular occlusion, haemorrhage, or inflammation. The initial progression of symptoms was suggestive of an inflammatory reaction rather than infarction or haemorrhage. The discrepancy in the time sequence between the febrile episode and the onset of ataxia makes direct invasion or an exotoxin unlikely. The delay of 21-26 days between the onset of fever and the ataxia suggests an immune mechanism. The selective effect on the cerebellar system and the response to steroids in some patients also favour this hypothesis.

Certain viruses such as rubella, rubeola, varicella, and mumps may produce acute ataxia as a parainfectious or postinfectious encephalomyelitis with an assumption of inclusion of a perivascular demyelinating process. ${ }^{34}$ The possibility of the malarial episode in some way activating a dormant neurotropic virus which subsequently produces the cerebellar damage cannot be excluded.

The epidemic of cases of ataxia may suggest a mutant strain of falciparum. Though the patients came from different localities, cross transmission among the localities was possible. Chloroquine resistant strains were encountered in two cases but were not a universal feature. As a host characteristic, a noteworthy feature was the absence of an enlarged spleen, even among patients permanently resident in malarious areas. This may be an indication of poor host resistance to invasion by the malarial organism. Work is in progress, in collaboration with the departments of parasitology and microbiology, with a view to identifying the parasite and host characteristics of these cases and examining the role of immune mechanisms in the causation of cerebellar damage.

I am grateful to Drs $M$ de $S$ Wijesundera and $J \mathrm{~S}$ Edirisinghe, of the department of parasitology, Dr J S M Peiris, of the department of microbiology, and Professor S Dissanayake, of the department of biochemistry, for their invaluable help in the investigation of these cases and Professor B D Dharmasena for advice.

\section{References}

1 Vietze G. Malaria and other protozoal diseases. In: Vinken PJ, Bruyn GW, eds. Handbook of clinical neurology. Vol 35. Infections of the neroous system-part III. Amsterdam: North-Holland Publishing Co, 1978:143-60.

2 Senanayake N, Wimalawansa SJ. Periodic paralysis complicating malaria. Postgrad Med $\mathcal{f}$ 1981;57:273-4.

3 Eley RC. Neurologic conditions in infants and children. J Pediatr 1935;7:248-76.

4 Miller HG, Stanton JB, Gibbons JL. Parainfectious encephalomyelitis and related syndromes. Qf Med 1956;25:427-505.

(Accepted 6 March 1987) 